\title{
Sol-Gel based Optical Ammonia Gas Sensor
}

\author{
Susanne Widmer $^{1,2}$, Marko Dorrestijn ${ }^{1}$, Edwin C. Constable ${ }^{2}$, Lukas J. Scherer ${ }^{1}$ \\ ${ }^{1}$ Empa, Swiss Federal Laboratories for Material Science and Technology, \\ Laboratory for Protection and Physiology, \\ Lerchenfeldstr. 5, St. Gallen, Switzerland \\ Correspondence: susanne.widmer@empa.ch \\ ${ }^{2}$ University of Basel, Department of Chemistry, \\ Spitalstr. 51, Basel, Switzerland
}

\begin{abstract}
State of the art gas sensors usually are hand-held devices. The development of a gas sensor system based on flexible polymer optical fibers, which finally can be integrated into textiles, would increase sensor wearability. As a model system, sol-gels with different mixtures of coumarin and fluorescein were coated on PMMA plates, which were exposed to gaseous ammonia. Significant differences in fluorescence intensity were observed for different dye mixtures. First sensor measurements with dyedoped sol-gel coated PMMA plates showed response to gaseous ammonia.
\end{abstract}

Key words: Ammonia sensor, polymer optical fibers, sol-gel, coumarin, fluorescein

\section{Introduction}

In recent years, various optical fiber based evanescent gas sensor systems have been reported [1-3]. The use of sol-gel materials as a porous support material has emerged as a promising means to produce glass fiber based chemical sensors [1,3]. However, glass fibers are too brittle to be integrated into textiles. Our aim is to coat dye doped sol-gels onto flexible polymer optical fibers (POFs) [4]. Flexible solgels can be obtained using organic modified silicates (ormosils) as the precursors instead of common orthosilicate precursors [5]. For proof of concept, sol-gels doped with coumarin (Cou) and fluorescein $(\mathrm{FI})$ dyes were prepared and spin coated on poly(methyl methacrylate) (PMMA) plates. Coumarin and fluorescein were chosen in combination, since this system exhibit a large Stoke shift due to the Förster resonance energy transfer (FRET) and a high quantum yield [6].

The sensitivity of the resulting xerogel films towards gaseous ammonia was measured with a gas sensor setup built in-house. Best dye mixtures and most efficient emission wavelength to detect gaseous ammonia were found using fluorescence spectroscopy.

\section{Experimental}

Gas-sensing sol-gels were produced by adding ormosil precursors, fluorescein (FI) and coumarin (Cou) to ethanol. The gelation was acid catalyzed. The PMMA plates were coated with sol-gel, followed by drying to form xerogel coated PMMA plates.

For fluorescence spectroscopy measurements, plates were pinched into a microtitre plate. The xerogels were exposed to gaseous ammonia by adding aqueous ammonia solutions into the wells.

For gas sensor measurements, coated plates were placed into a gas sensor setup (Fig. 1).

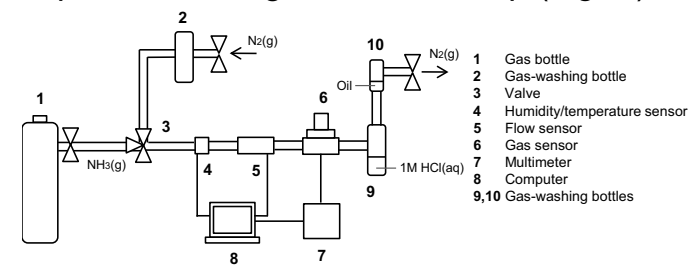

Fig. 1. Gas sensor setup

\section{Results and Discussion}

Best emission intensities for $\mathrm{Cou}$ and $\mathrm{FI}$ and Cou/FI mixtures were found by excitation at 375 $\mathrm{nm}$ and $481 \mathrm{~nm}$, respectively. Cou xerogels emitted with one band centered at $447 \mathrm{~nm}$ whereas $\mathrm{FI}$ xerogels emitted with a main band at $540 \mathrm{~nm}$ and a slight shoulder at $520 \mathrm{~nm}$, which corresponds to the anionic and dianionic forms [7] (Fig. 2). For Cou/FI mixtures, different spectra were obtained which is due to FRET. For fluorescence spectroscopy studies, the same conditions as in the sensor system were imitated by exposing xerogels to water vapour and gaseous ammonia. Water vapour had no significant effect on the absorption/emission wavelengths or fluorescence intensity. In Cou/FI 
mixtures, the Cou emission at $447 \mathrm{~nm}$, as well as $\mathrm{Fl}$ emission at $518 \mathrm{~nm}$ were almost entirely quenched when exposed to gaseous ammonia (Fig. 2).

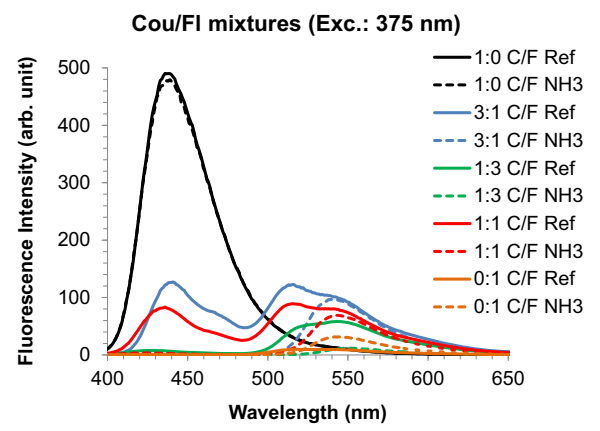

Fig. 2. Emission spectra (excitation at $375 \mathrm{~nm}$ ) of Cou/FI mixtures. Ref: xerogel coated plates with corresponding dye mixture. NH3: sol-gel coated plates exposed to $1.3 \% \mathrm{NH}_{3}(\mathrm{aq})$.

The spectra revealed that excitation at $375 \mathrm{~nm}$ and detection of emission at 400-500 nm gave the highest response signals. Further fluorescence experiments on different ratio of $\mathrm{Cou} / \mathrm{FI}$ in the sol-gel showed that the $1: 1 \mathrm{Cou} / \mathrm{FI}$ mixture is a promising candidate for sensing ammonia gas (Fig. 3).
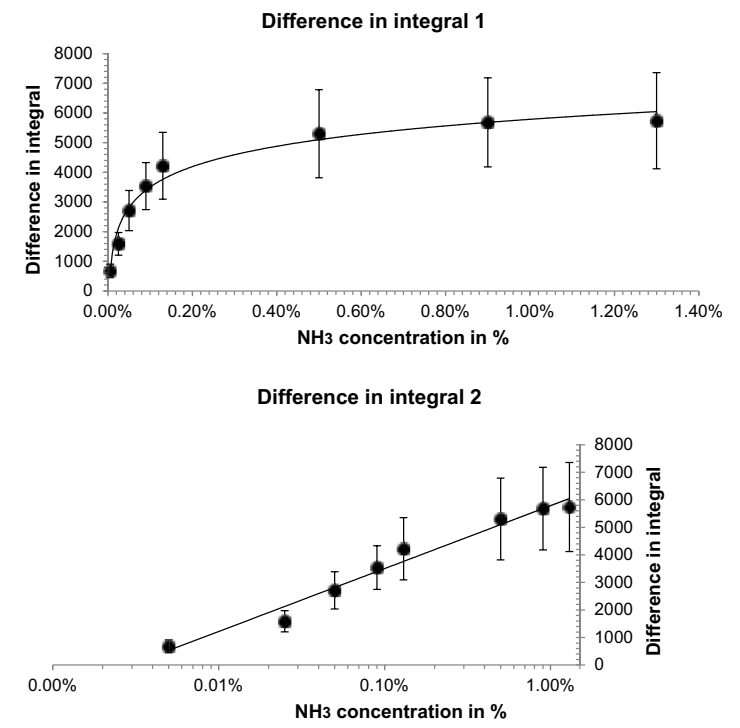

Fig. 3. Emission peak area vs. $\mathrm{NH}_{3}$ concentration for Cou/FI=1:1 (linear and semilog plots). The peak area is defined as the increase in the integral of the emission spectrum from $408-460 \mathrm{~nm}$.

The trend is approximately - although not strictly - logarithmic. The exposure to different concentrations of ammonia of only Cou or $\mathrm{FI}$ doped xerogels showed limited sensitivity when excited at 375 respectively $481 \mathrm{~nm}$ and no trend could be observed. This finding indicates that the FRET between the dyes played an important role in the sensing mechanism. High dye concentrations did not lead to higher fluorescence emission due to self-quenching. Gas sensor measurements were performed on a 1:1 Cou/FI xerogel (Fig. 4).

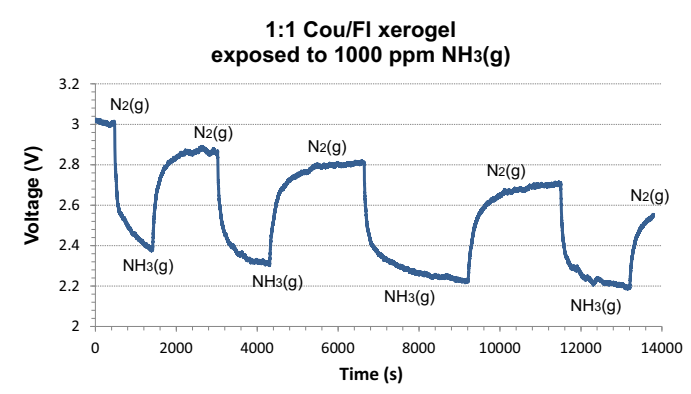

Fig. 4. Gas sensor measurements on 1:1 Cou/FI xerogel on PMMA. The plate was illuminated at $375 \mathrm{~nm}$ from the top. A band pass filter allowed light from 408-460 $\mathrm{nm}$ reaching the perpendicular installed detector. By turning the valve it could be alternated from $\mathrm{N}_{2}(g)$ to $\mathrm{NH}_{3}(\mathrm{~g})$ (1000 ppm).

The sensor measurements confirmed the usefulness of the ormosil-PMMA system as a sensor system. The decrease in fluorescence at $440 \mathrm{~nm}$ due to the presence of ammonia leads to a fast decrease in voltage. The detection limit was below $100 \mathrm{ppm}$. The effect is reversible and reproducible when the sensor is flushed with $\mathrm{N}_{2}(\mathrm{~g})$. A baseline shift was observed which is may be caused by irreversible adsorption of a certain ammonia amount from the xerogel and/or from thermal drift of the electronics. An undoped xerogel was measured as a reference that did not show any decrease or increase in voltage when exposed to gaseous ammonia.

\section{Conclusion}

PMMA plates coated with dye doped sol-gels were used as a model for POF ammonia gas sensing. Optimal Cou/FI mixtures and excitation/emission wavelengths were found using fluorescence spectroscopy leading to a linear $\mathrm{NH}_{3}$ response. First measurements with a gas sensor device showed sensitivities of low ppm values. Once the sensor system has been optimized, it will be applied to POFs. The final integration of this technology into textiles will lead to higher sensor wearability. This platform technology can be applied to detection of other toxic industrial chemicals (TICs) and chemical warfare agents (CWAs) to protect employees in chemical industries and first responders.

\section{Acknowledgements}

We gratefully thank J. Gschwend and his workshop team for the implementation of our sensor designs. 


\section{References}

[1] S. T. Lee, et al, Journal of Optics A: Pure and Applied Optics 3, 355-359 (2001); doi:10.1088/1464-4258/3/5/307

[2] Y. Huang, S. Tao, Journal of Sensor Technology 1, 29-35 (2011); doi: 10.4236/jst.2011.12005

[3] B. D. Gupta, S. Sharma, Optics Communications 154, 282-284 (1998); doi: $10.1016 / \mathrm{S} 00304018(98) 00321-6$

[4] M. Dorrestijn, et al, The 14th International Meeting on Chemical Sensors, Nürnberg, Germany, 448-449 (2012); doi: 10.5162/IMCS2012/5.2.5

[5] Y. Hu, J. D. Mackenzie, Journal of Materials Science 27, 4415-4420 (1992); doi: 10.1007/BF00541574

[6] D. M. Goodall, D. R. Roberts, Journal of Chemical Education 62, 711-714 (1985); doi: 10.1021/ed062p711

[7] R. Sjöback, J. Nygren, M. Kubista, Spectrochimica Acta Part A: Molecular and Biomolecular Spectroscopy 51, L7-L21 (1995); doi: 10.1016/0584-8539(95)01421-p 